\title{
Hydrocarbon accumulation patterns of Shaximiao Formation in Longgang, Sichuan Basin
}

\author{
WANG Zhiguol, JIN Weil, CHENG De'an ${ }^{1}$ \\ ${ }^{1}$ Exploration and Development Research Institute of Daqing Oil Field Co. L td, Daqing City, Heilongjiang Province, 163712,China
}

\begin{abstract}
Recent years, progress has been made in hydrocarbon exploration of Shaximiao Formation in Sichuan Basin. The Shaximiao formation is fluvial facies deposit, the reservoir is channel sandstone with a low porosity and permeability, oil and gas generate from black shale of the Lianggaoshan formation and the Da'anzhai section of Ziliujing formation. In Longgang, immigration channel is the key condition of accumulation of Shaximiao formation. There are two kinds of immigration channels, fractures caused by hydrocarbon generation overpressure release and faults. Oil generated from Lianggaoshan shale immigrated to the sandstone of bottom part of Sha1, oil and gas generated from Da'anzhai black shale immigrated to upper part sandstone though faults. There is no water in the reservoir. Channel sandstone and source faults interpretation is the key point of exploration success.
\end{abstract}

\section{1 preface}

Jurassic is the only oil-producing stratum in Sichuan Basin. Recently, important improve have been made in Shaximiao formation's exploration. It shows a better prospect. Because of its shallow burial depth, oil recovery of Shaximiao formation has more economic benefits than oil and gas recovery of other layers. The maximum oil test output reached 170 tons per day.

\section{Sedimentation and stratigraphy}

In the early and middle Jurassic, Sichuan Basin is a large depression basin formed on the basis of Triassic foreland basin. Until the late early Jurassic, the paleoclimate of Sichuan Basin was warm, moist and rainy, then, the climate gradually became hot and dry, and the red layer appeared.

During the Da'anzhai period, the Sichuan basin was a large freshwater lake basin and carbonate rocks were widely distributed, only a few delta facies clastic rocks distributed along the periphery of the basin. During this period bivalves flourished, as did some gastropods, ostracoda and fish, the deep and semi deep lake was mainly located in Gongshanmiao, Longgang and Pingchang, black calcareous organic rich shale, 30 to 60 meters thick, was deposited in the Da'anzhai section there.

In the Lianggaoshan period, the detrital provenance of Sichuan basin mainly came from three directions: the western, the southeastern and the northern, the sediments were mainly delta lacustrine facies. The Dabashan clastic source on the north area is the main supply area of the basin. Controlled by the orogenic belt, a complete sedimentary evolution sequence of delta fringe, shallow lake, semi deep lake and deep lake was formed from bottom to top, 30 to 60 meters thick black organic rich shale was deposited in the Lianggaoshan top part.

Shaximiao is a middle Jurassic formation with a thickness of 1200-2100m. In the early Shaximiao period, the clastic material in the periphery of the basin was abundant, and the delta deposits with long-distance distributary channels are distributed in most areas of Sichuan basin. At this time, the basin water became shallow, the climate changed to semi-arid, and the tectonic activity weakened. The river channels and flood plains were widely distributed in the basin. The lithology of the Shaximiao is characterized by purple and grayish green thick mudstone intercalated with sandstone. The reservoir of the Shaximiao formation mainly deltaic deposits, Longgang is located in the delta fringe facie, branch channel sand is the main reservoir rock. The detrital material of Shaximiao Formation came from the northeast and channel sedimentary sand extend from northeast to southwest (Fig.1).

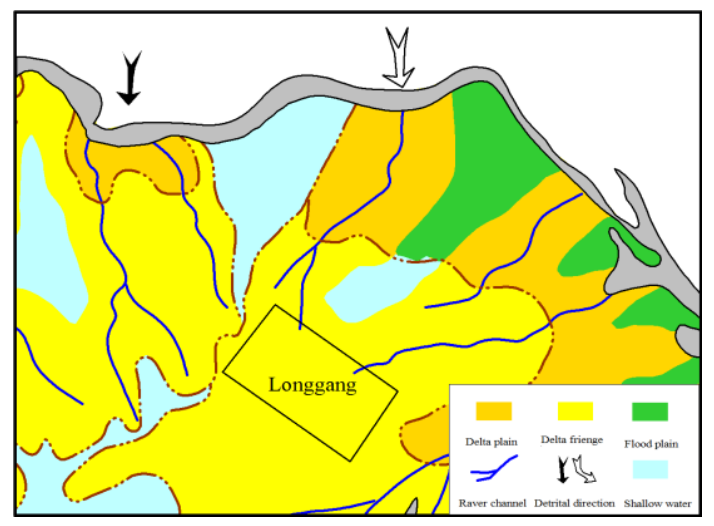

\footnotetext{
* Corresponding author: dqzhouyue@ petrochina.com.cn
} 
Fig. 1 The sedimentary facies map of shaximiao in Longgang

Shaximiao formation is divided into Shal and Sha2. The lower 40 to 50 meters of the Shal is shallow lacustrine deposit, the lithology is green mudstone, siltstone and fine sandstone. and the upper part is fluvial facie deposit. The Sha2 is fluvial facie and bay facie, and its lithology is purple mudstone intercalated with green siltstone. The lower part of Lianggaoshan formation is mainly composed of grayish green mudstone and light gray argillaceous siltstone sandstone, the upper part is mainly composed of dark gray and grayish black shale, intercalated with siltstone and fine sandstone. In Da'anzhai section, there are bioclastic limestone above and black shale below (Fig.2)

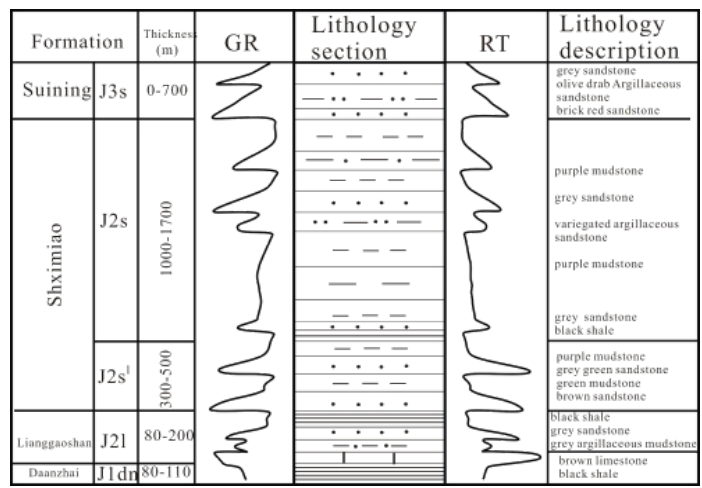

Fig. 2. Stratigraphic histogram of Longgang

\section{Hydrocarbon source of the Shaximoao}

The Shaximiao formation itself can't generate hydrocarbon, oil and gas came from the Lianggaoshan black shale and Daanzhai black shale below it. The Da'anzhai section is early Jurassic in age, its range from 30 to 60 miters thick, occurs below the Lianggaoshan formation and above the Maanshan section, belong to the Ziliujing formation, and burried from 1400 meters to 4500 miters in the Longgang block. The Da'anzhai section was deposited in interactive high-energy and low-energy lake water far enough from shore. The Da'anzhai is a set of black calcareous shale interlaced brown biolimestones, the core analysis shows that the total organic carbon content in The Da'anzhai shale is $0.5-3.5 \%$. In 691 samples, those TOC $>1.0 \%$ accounted for $56.44 \%$. The type of organic matter is mainly kerogen types II .The Da'anzhai shale has a high thermal maturity placing it in the dry gas or condensate range. In Sichuan basin, the hydrocarbon generation intensity of Da'anzhai section is distributed in the range of 100000 to 600000 tons per square kilometre. Longgang block is just located in the hydrocarbon generation center of Da'anzhai shale. The total thickness of black shale in Lianggaoshan formation is 70-90 meters. The TOC of the source rocks of Lianggaoshan formation is more than $1.3 \%$, the average content of chloroform asphalt "a" is more than $0.15 \%$, and the average content of total hydrocarbon is more than $1000 \mathrm{ppm}$. The vitrinite reflectance of the source rocks of Lianggaoshan formation is between $1.1 \%$ and $1.4 \%$, and the hydrocarbon generation intensity of Lianggaoshan formation is 800000-190000 tons per square kilometre.

\section{Reservior}

The channel sand of the Shaximiao in Longgang generally 0.6-3.2 kilometres wide with a maximum width of 24 kilometres. The channel sand commonly 520 meters thick, the maximum thickness can reach 35 meters. The channel can be clearly seen on the maximum amplitude attribute map of 3-D seismic (Fig.3).

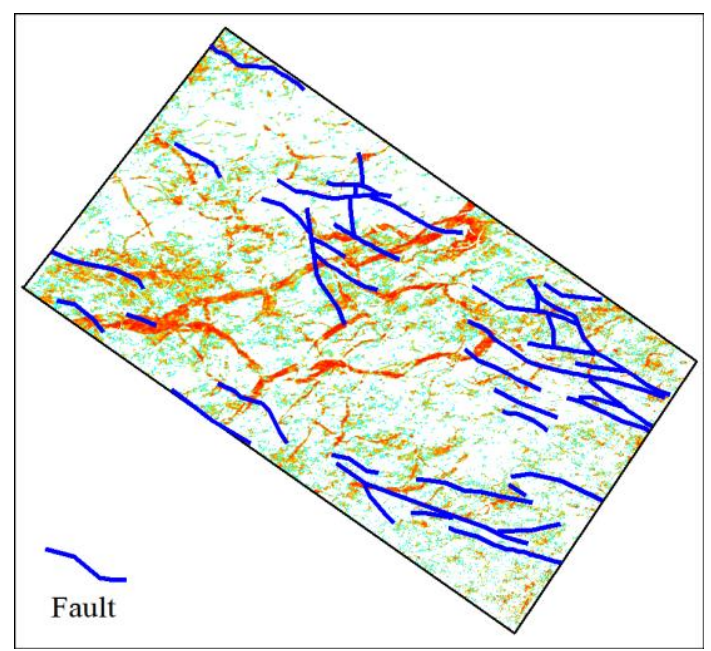

Fig. 3 Maximum peak amplitude attribute map of Longgang

The main rock type of Shaximiao reservoir is feldspathic lithic sandstone and lithic arkose. The average content of quartz in sandstone is $54.2 \%$; the average content of feldspar is $17.8 \%$, mainly orthoclase and plagioclase, followed by microcline; the average cuttings are $28.0 \%$, mainly composed of sedimentary debris, followed by magmatic debris and metamorphic debris (Fig 4).

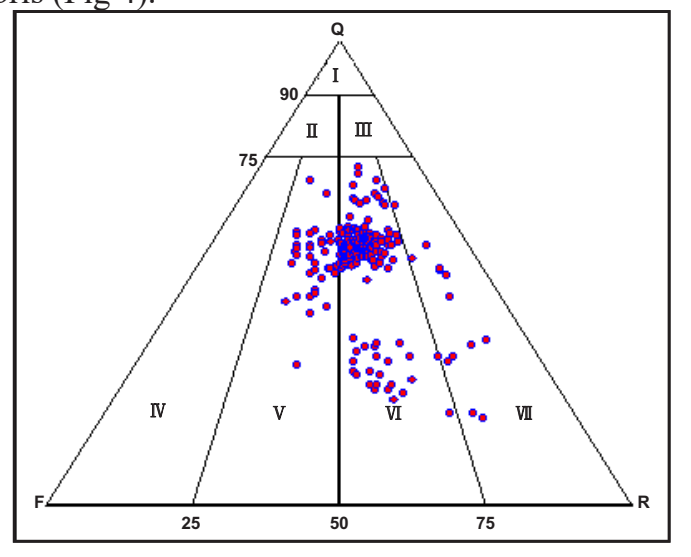

Fig.4. Shaximiao sandstone type in Longgang block

The storage space is mainly composed of residual primary pores and dissolved pores, and some cracks. The primary pores are mainly residual interparticle pores and intercrystal pores, which mostly occur between the particles and the crystals with less interstitial materials. Due to the secondary enlargement of quartz, the 
cementation of chlorite rim and authigenic quartz, the pore size is further reduced and the shape is often polygonal. The pore diameter is generally less than $0.05 \mathrm{~mm}$.

According to the characteristics of dissolution, the secondary pores can be divided into interparticle dissolved pores, intraparticle dissolved pores, moldic pores, cement internal dissolved pores and heterobase internal dissolved pores. interparticle dissolved pores and intraparticle dissolved pores are the main ones, while moldic pores, cementation dissolved pores and matrix internal dissolved pores are rare.

There are two kinds of cracks: structural fractures and dissolution fractures. The strike and tendency of structural fractures are consistent with the fractures, and the size varies greatly. The length is generally $5 \sim 10 \mathrm{~mm}$, the width of the fractures is generally below $0.02 \mathrm{~mm}$, and some are up to $0.03 \mathrm{~mm} \sim 0.05 \mathrm{~mm}$. Such fractures extend far and distribute widely, connecting the pores. Dissolution joints were formed when the fluid flowed through the pores and throat and melted the particles and intraparticle materials on both sides of the joint surface. The fracture wall is extremely irregular, with a length of $0.5 \mathrm{~mm}$ to $1.5 \mathrm{~mm}$ and a width of $0.03 \mathrm{~mm}$ to $0.25 \mathrm{~mm}$. Such fractures were well connected to pores and contributed greatly to the storage and permeability of oil and gas.

The pore throat frequency histogram shows that the pore throat radius ranges from $0.0038 \mu \mathrm{m}$ to $9.375 \mu \mathrm{m}$, while the pore throat distribution from $0.0092 \mu \mathrm{m}$ to $2.3438 \mu \mathrm{m}$ has obvious peak. Most of the pore skewness values are positive and relatively large, which reflects that the sandstone has a certain amount of medium and large pore throat and certain storage and permeability capacity. The variation coefficient is between 0.08 and 1.3, with an average of 0.27 . The sorting coefficient is between 1.17 and 5.37, with an average of 2.63, indicating that the distribution of pore throat is relatively concentrated and the sorting property is relatively good (Fig.5).

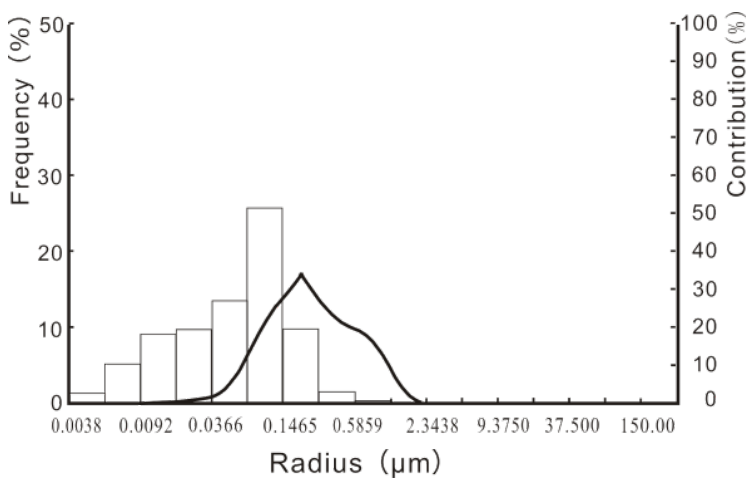

Fig.5 The pore throat frequency histogram of Shaximiao Analyzing 327 core porosity samples from Shaximiao sandstone, the porosity range is relatively large, ranging from $0.23 \%$ to $7.92 \%$, with an average of $3.25 \%$. The porosity is mainly distributed between $1 \%$ and $6 \%$, accounting for $98.47 \%$. The porosity of $>3 \%$ rock samples accounted for $51.68 \%$ (Fig.6a). The permeability analysis of 297 core samples shows that the permeability of Shaximiao sandstone is distributed between $0.000001 \mathrm{mD}$ to $3.57 \mathrm{mD}$, with an average of $0.35 \mathrm{mD}$, among which the permeability of $53.2 \%$ samples is less than $0.01 \mathrm{mD}$ (Fig. 6b).

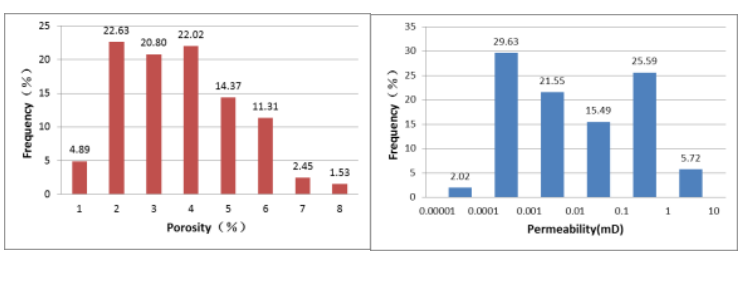

$$
\text { a. Porosity b. Permeability }
$$

Fig.6. Frequency histogram of sandstone's properties

\section{Hydrocarbon migration pathways}

There are two kinds of hydrocarbon migration pathways for Shaximiao channel sandstone, fault and fractures. The faults in Longgang are all reverse faults. the strike of the fault is mostly NW-SE or EW, these faults are distributed in belts, break up from Leikoupo Formation and end of the middle of Sha2. Most of the faults are 5$10 \mathrm{~km}$ long with the longest $26 \mathrm{~km}$, The fault throw is mainly 100 to 300 meters, the maximum is 600 meters, their dip angles are 45 to $70^{\circ}$ with the lowest $30^{\circ}$ and the highest $75^{\circ}$ (Fig 3).

Fracture act as both the migration channel and the space of oil and gas. There are two kinds of fractures, tectonic fissure and micro fractures cause by hydrocarbon generation pressure release from source rock. Fractures can be obviously found in the cores of high-yield wells, but those no fracture wells barely achieved industrial oil flow (Fig.7).

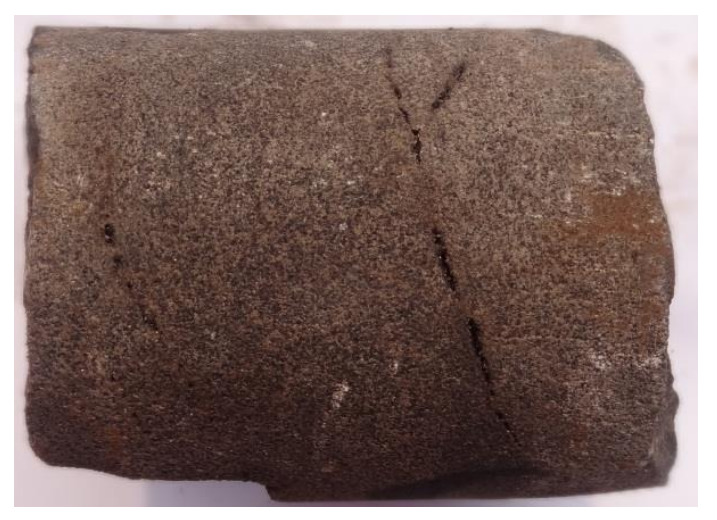

Fig. 7 Fractures in borehole core of Shaximiao sandstone

\section{Hydrocarbon accumulation pattern}

There are two hydrocarbon accumulation patterns in Shaximiao channel sandstone. Pattern one is "direct type", mains oil and gas move from source rock to reservoir directly. The Lianggaoshan shale produced very high overpressure during hydrocarbon generation, under the pressure, fractures formed and oil was pressed into the sandstone within 50 meters high from Shaximiao Bottom Boundary which is called "Guankou" sandstone. The other pattern is "indirect type", oil and gas move 
from source rock to reservoir through fault. The porosity of limestone and shale in Lianggaoshan and Da'anzhai is too low to hold all the oil and gas, oil and gas was forced to migrate upward and enter Shaximiao channel sand through faults. Early hydrocarbon generation term, the main product was oil, so oil filled the sandstone it contact with sequentially. With the increase of thermal evolution, natural gas generated, the lower restore space had been filled with oil, gas had to move upper. Because of the very low porosity and permeability, buoyancy has no any effect on the formation of oil and gas reservoirs. All oil and gas reservoirs were formed by primary migration, overpressure of hydrocarbon generation was the driving force, oil and gas pushed the water in the sandstone pores away and took the place. The overpressure with pressure coefficient of 1.4 to 1.9 still remained in Da'anzhai shale now day. The tectonic height is irrelevant to accumulation (Fig 8).

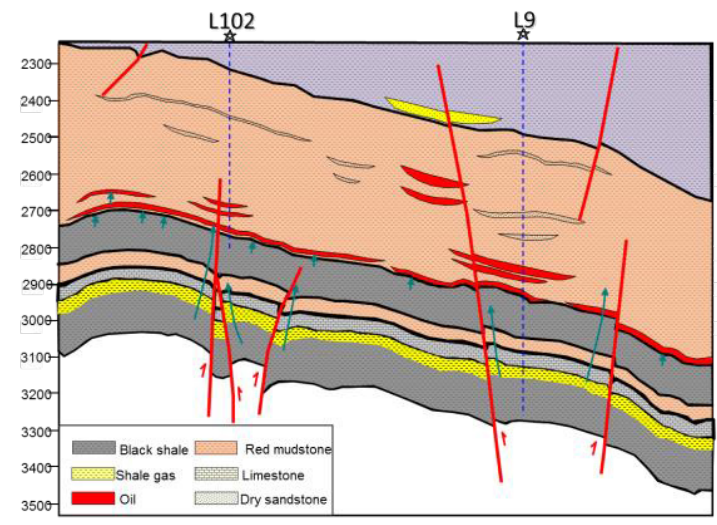

Fig.8 Hydrocarbon accumulation pattern of Shaximiao Formation in Longgang

\section{Conclusion}

The conditions of accumulation were source, fault and storage space, in Longgang block, the condition of source rocks are almost the same, so is the reservior condition, source fault is the key factor the formation of oil and gas reservoirs.

\section{References}

1. LIU Dawang 2018 Rock Types and Their Association Characteristics and Significance for Exploration in the Da'anzhai Member, Eastern Sichuan(Science Technology and Engineering) 2018:pp73-80

2. Jie Ren,Fu Zhao, Binchun Qin, Zhenxiang Li 2020 (Charactistics and Main Controlling Factors of High-Quality Reservoirs in the $1^{\text {ST }} \mathrm{Member}$ of Shaximiao Formation, Longgang Area, Central Sichuan) Journal of Oil and Gas Technology 2020,42(1):PP1-12

3. Chen Shijia, Gao X ingjun, Wang Li , Lu Jungang, Liu Chaowei, Tang Haiping, Zhang Huanxu, Huang Y oulin , Ni Shuai, 2014 (Factors controlling oiliness of Jurassic Lianggaoshan tight sands in central Sichuan Basin, SW China) Petroleum Exploration and Development 2014,41(4): PP421427

4. Jia Chengzao, Zheng M in, Zhang Y ongfeng. 2012 (Unconventional hydrocarbon resources in China and the prospect of exploration and development) Petroleum Exploration and Development 2012, 39(2):PP 129-136

5. Liang Digang, Ran Longhui, Dai Danshen, et al. 2011 (A re-recognition of the prospecting potential of J urassic large-area and on conventional oils in the central-northern Sichuan B asin) A cta Petrolei Sinica 2011, 32(1): PP8-17

6. SUN Wei, LI Zhi-wu, ZHANG Wei, FENG Feng, ZHANG Meng, WU Wen-hui 2014 (Petroleum exploration prospect of Lower Jurassic Da@nzhai Member, north-centre of Sichuan Basin, China) Journal of Chengdu University of Technology (Science \& Technology Edition) 2014 41(1):PP1-7

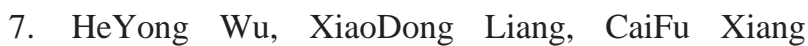
Y ueW en Wang 2007 (Characteristics of petroleum accumulation in syncline of the Songliao basin and discussion on its accumulation mechanism) Science in China Series D: Earth Sciences volume, 2007,50:PP 702-709 